\title{
Effect of Chain Extenders on Polyurethanes Containing Both Poly(butylene succinate) and Poly(ethylene glycol) as Soft Segments
}

\author{
Suk-Young Moon, Young-Deok Park, ${ }^{+}$Cheol-Ju Kim, ${ }^{\dagger}$ Chan Hee Won, and Youn-Sik Lee ${ }^{\star}$ \\ Division of Enironmental and Chemical Engineering. The Research Institute of Industrial Technologv. \\ Engineering Research Institute. Chonbuk National Universin, Chonju 561-756. Korea \\ Department of Chemistrv. Chonbuk National Lniversin, Chonju $561-756$, Korea \\ Received April 10,2003
}

Key Words : Polỵurethane. Chain extender. Soft segment. Hard segment

Polyurethanes have been widely used industrially due to their versatile properties. ${ }^{1.2}$ Some of them are biodegradable and have been used as biomaterials. ${ }^{3}$ Biodegradable polyurethanes may be able to replace nondegradable polymers such as polyethylene and polypropylene in fabrication of packaging films in near future as long as their mechanical properties are comparable to those of the common filmforming materials.

Polyurethanes containing poly(ethylene glycol) (PEG) are interesting since the hydrophilic PEG segments can enhance the degradation. Furthermore. PEG itself has been frequently used as comonomers in preparing biodegradable polymers due to its good biocompatibility and biodegradability, ,s Recently. polyurethanes were synthesized from poly(butylene succinate) (PBS), PEG, and 4.4'-dicyclohexylmethane diisocyanate $\left(\mathrm{H}_{1=}=\mathrm{MDI}\right)$ without using any chain extender in order to obtain moderate molecular weights. ${ }^{\circ}$ PBS, a crystalline polymer, was employed in order to raise the melting temperature $\left(\mathrm{T}_{N 1}\right)$ of the resulting polyurethanes. which may facilitate their fabrication process. But. the molecular weights of the polyurethanes were not high enough to show desirable mechanical properties even though their hydrolytic degradations were efficient.

Polyurethanes were also synthesized from PBS, PEG, and $\mathrm{H}_{12}$ MDI by using 1,4-butanediol (BD) as chain extender. ${ }^{7}$ Their number-average molecular weights and melting temperatures were found to be in the range of 30.000-38.000 and $99-101{ }^{\circ} \mathrm{C}$, respectively. The tensile strengths $(2.0-2.4$ $\mathrm{kg} / \mathrm{mmm}^{3}$ ) of the polymers were slightly greater than the reported value of PBS $\left(1.6 \mathrm{~kg} / \mathrm{mm}^{3}\right)$ with a comparable molecular weight $\left(\mathrm{M}_{n} 20,000\right){ }^{\mathrm{S}}$ Their elongations at break $(230-330 \%)$ were significantly greater than that of the PBS $(42 \%)$. but still not satisfactory for fabrication of packaging films.

In the present study, $\mathrm{H}_{12} \mathrm{MDI}-$ based polyurethanes were prepared by using PBS/PEG $(2 / 1 \mathrm{~mol} / \mathrm{mol})$ as soft segnents. Three different combinations of chain extenders such as $\mathrm{BD}$ (PU-1), BD/ED (1/1) (PU-2). and ethylenediamine (ED) (PU-3) were entployed to synthesize the polyurethanes. This paper discusses briefly some thermal and mechanical

\footnotetext{
${ }^{*}$ To whom correspondence should be addressed. E-mail: yosklear âche.chonbuk.ac.kr
}

properties of the resulting polymers.

\section{Experimental Section}

Synthesis. The synthetic route to the polyurethanes is illustrated in Scheme 1. PBS was prepared by employing the reported procedure. ${ }^{67}$ The $\mathrm{M}_{n}$ of PBS was calculated to be about 1,620, based on the hydroxy (67.4) and acid values (1.65). PBS ( $30 \mathrm{~g} .18 .5 \mathrm{mmol}$ ) was dried at $70^{\circ} \mathrm{C}$ for $24 \mathrm{~h}$. and melted together with $P E G_{100 !}\left(M_{n}=1000.9 .26\right.$ g. 9.26 mmol) at $120-130{ }^{\circ} \mathrm{C}$ in a reaction flask. followed by the addition of $\mathrm{H}_{1}$ MDI $(9.70 \mathrm{~g} .37 .0 \mathrm{mmol})$ for $2 \mathrm{~h}$ under a nitrogen atmosphere. After the formation of NCO-terminated prepolymer was confirmed, BD (0.83 g. $9.26 \mathrm{mmol})$ and DMF ( $120 \mathrm{~g})$ were added. The resulting solution was reacted in the presence of dibutyltin dilaurate $(0.02 \%)$ at the same temperature until the isocyanate group disappeared based on the FT-IR spectrum $\left(-2270 \mathrm{~cm}^{-1}\right)$. The resulting mixture was cast in a mold and heated at $70^{\circ} \mathrm{C}$ and 50 torr for $24 \mathrm{~h}$ to complete the polymerization and at the same time to remove DMF. The resulting polymer was precipitated into methanol in order to remove any remaining starting materials and impurities. The purified polyurethane is designated as PU-I. PU-2 and PU-3 were prepared by following the same procedure, but using $\mathrm{BD} / \mathrm{ED}(\mathrm{l} / \mathrm{l})$ and $\mathrm{ED}$. respectively, instead of $B D$ as chain extenders.

Measurements. The thermal transitions of polymers were observed with differential scanning calorimetry (DSC, DuPont 2000). The number- and weight-average moleculatr weights $\left(\mathrm{M}_{\mathrm{y}} / \mathrm{M}_{\mathrm{w}}\right)$ of the polymers were measured with gel permeation chromatography (GPC Maxima 820) in chloroform using polystyrene standards. The tensile strength, elongation at break and modulus were measured with a universal test machine (Lloyd Co.) at a strain rate of $50 \mathrm{~mm} /$ $\mathrm{min}$. The wide angle $\mathrm{X}$-ray diffraction was studied using a $\mathrm{X}$-ray diffractometer (Rigaku. Co., Cu target) at $40 \mathrm{kV}$ and $30 \mathrm{~mA}$.

\section{Result and Discussion}

The $\mathrm{M}_{\mathrm{n}}$ of PU-2 is slightly greater than those of PU- 1 and PU-3, but the $\mathrm{M}_{w}$ of the polymers are pretty close to each other. as shown in Table 1. The DSC themograms obtained 


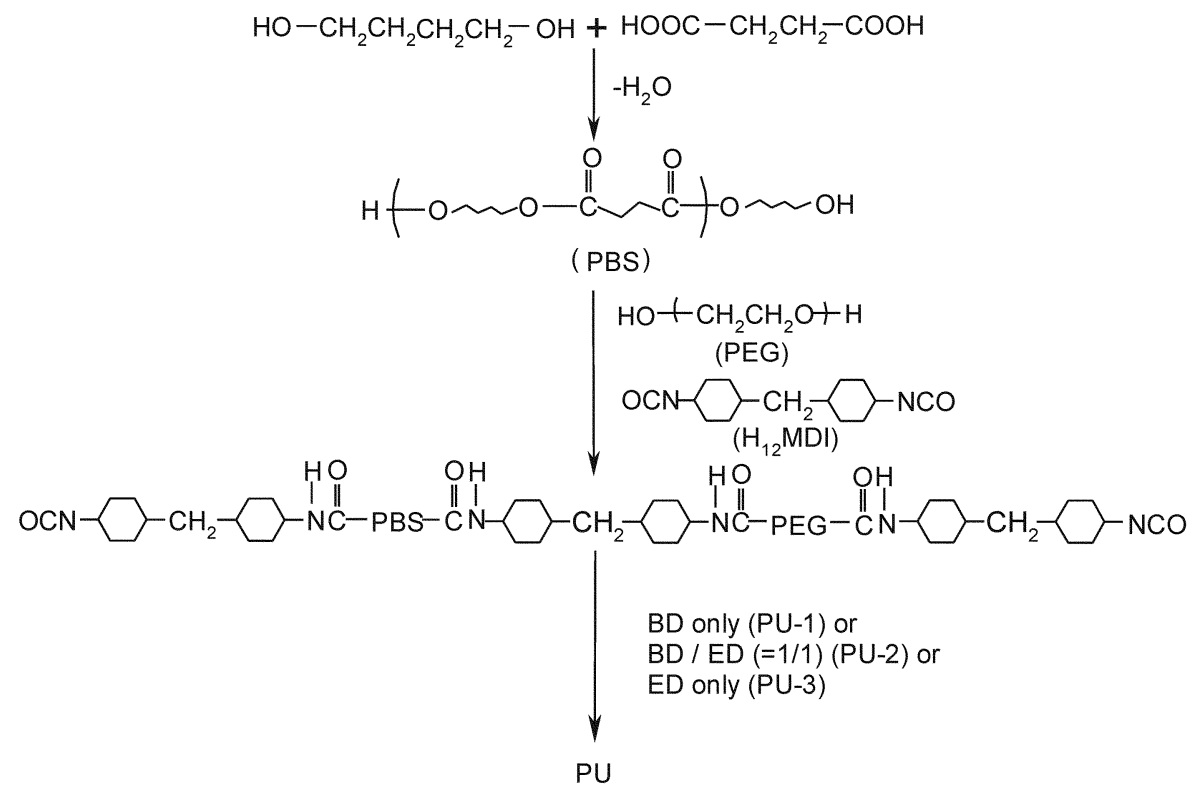

Scheme 1. Schematic representation of a synthetic route to PL:-1. PL:-2. and PU-3.

from the second heating scans are illustrated in Figure I. The glass transition temperatures $\left(\mathrm{l}_{\mathrm{c}} \mathrm{s}\right)$ of the polymers are very close to each other. The $\mathrm{T}_{11} \mathrm{~s}$ of $\mathrm{PU}-1, \mathrm{PU}-2$, and $\mathrm{PU}-3$ at maximum heat capacity were measured to be 104, 101, and $105^{\circ} \mathrm{C}$, respectively, while that of PBS was $113^{\circ} \mathrm{C}$. This result suggests that the melting transitions arise from the l'BS segments in the polyurethanes. ${ }^{6,7}$ On the other hand, the P'EG seginents of these polymers did not show any melting transition in the same temperature range even though the $I_{\text {II }}$ of the $\mathrm{P}^{\prime} \mathrm{EG} \mathrm{G}_{100}$ itself is $39^{\circ} \mathrm{C}$. P'olyurethanes were prepared using $\mathrm{P}^{2} \mathrm{E} \mathrm{G}_{1000}$ or $\mathrm{P}^{2} \mathrm{E} \mathrm{G}_{2000}, \mathrm{H}_{12} \mathrm{MDI}$ and $\mathrm{BD}$. Polyurethanes prepared from ${ }^{\prime} \mathrm{EG}_{1000}$ did not exhibit any melting transition while those prepared from ${ }^{3} E G_{200 n}$ showed a $\mathrm{T}_{\mathrm{I}+1}$ at about 38 ${ }^{\text {" }} \mathrm{C}$ (data not shown). This result indicates that the absence of melting transition of PEG soft seginents in the present polyurethanes is due to the low molecular weight of the PEG employed. Any $T_{11}$ of the hard segments was not observed in the temperature range up to $250^{\circ} \mathrm{C}$. The absence of melting transition of hard segments in our present polyurethanes results from the inefficient packing of the segments because $\mathrm{H}_{12} \mathrm{MDI}$ exists in three different isomers of cis-trans, transrans and cis-cis conformations."

The $T_{11}$ and $\Delta \mathrm{H}_{31}$ values of PU-2 are lower than those of $P U-I$ and PU-3. In the case of PU-2, the isocyanate- terminated prepolymers react with $\mathrm{BD}$ and $\mathrm{ED}$ in the chain extension reaction step, resulting in the formation of urethane and urea groups in their hard segments, respectively. PU-I contains urethane groups in the hard segments, but

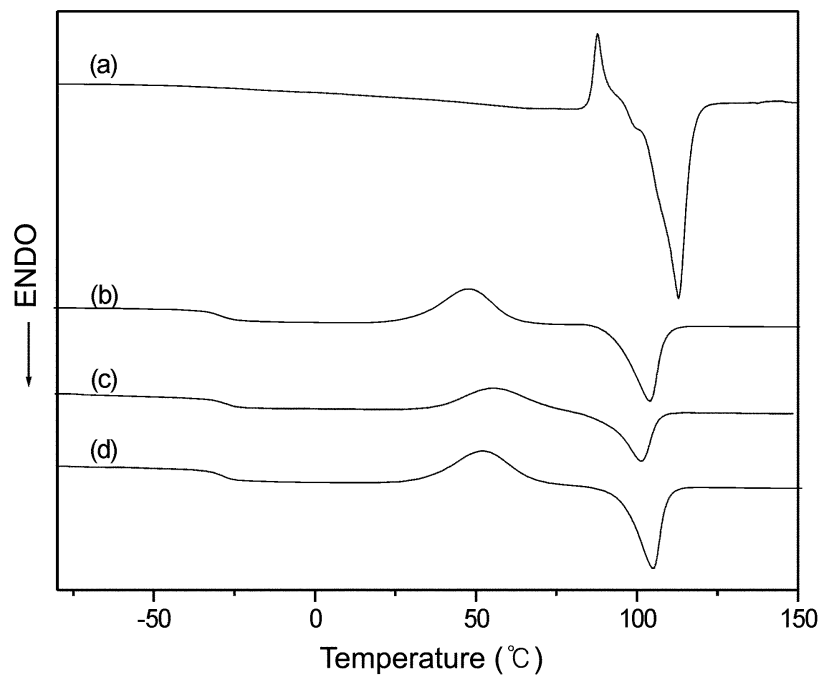

Figure 1. DSC thermograms obtained on the second heating seans: (a) PBS. (b) Pl-1. (c) Pl -2. and (d) PL:-3 (scan rate. $10^{\circ} \mathrm{C} / \mathrm{min}$ ).

Table 1. Average molecular weight $\left(\mathrm{M}_{\mathrm{w}} / \mathrm{M}_{w}\right.$ ). glass transition temperature ( $\mathrm{l}_{\mathrm{g}}$ ) melting transition temperature ( $\mathrm{T}_{\mathrm{m}}$ ). melting transition enthalpy $\left(\Delta \mathrm{H}_{\mathrm{m}}\right)$. tensile strength. clongation at break. and modulus of synthesized polyurethanes. The $\mathrm{T}_{\mathrm{m}}$. $\mathrm{T}_{\underline{m}}$ and $\Delta \mathrm{H}_{\mathrm{m}}$ were measured from the second heating scanned DSC thermograms

\begin{tabular}{|c|c|c|c|c|c|c|c|c|c|}
\hline I'l! & $\mathrm{M}_{11}$ & $\mathrm{M}_{\mathrm{w}}$ & $\mathrm{T}_{3}\left(1^{\circ} \mathrm{C}\right)$ & $\mathrm{I}_{\mathrm{n}}\left({ }^{\circ} \mathrm{C}\right)$ & $\Delta \mathrm{I}_{\mathrm{t}}(\mathrm{cal} / \mathrm{g})$ & $\begin{array}{c}\text { Tansile strength } \\
\left(\text { kgfo } \mathrm{mm}^{2}\right)\end{array}$ & $\begin{array}{l}\text { Elongation at } \\
\text { bratak }(\%)\end{array}$ & $\begin{array}{l}\text { Modulus } \\
\left(\mathrm{kgf} / \mathrm{mm}^{2}\right)\end{array}$ & $\begin{array}{l}\text { Hard sigment } \\
(w+\%)\end{array}$ \\
\hline PBS & 1.620 & - & - & 113 & 22.1 & - & - & - & - \\
\hline$P(1-1$ & 16.000 & 42.000 & -32 & 104 & 10.5 & 1.7 & 410 & 12.0 & 21.3 \\
\hline $\mathrm{Pl}-2$ & 20.000 & 47.000 & -31 & 101 & 7.0 & 1.9 & 1100 & 13.0 & 21.1 \\
\hline Pl!-3 & 15.000 & 41.000 & -32 & 105 & 10.3 & 2.0 & 140 & 14.0 & 21.0 \\
\hline
\end{tabular}


PU-2 contains equal amounts of urethane and urea groups. On the other hand. [PU-3 contains only urea groups in the hard segments. Urea groups have two nitrogen atoms suitable to form hydrogen bonds, whereas urethane groups have only one nitrogen in this case. The two different groups in PU-2 cannot be closely packed together in the same hard domains due to the misinatching of their chemical structures as well as the isomeric nature of $\mathrm{H}_{12} \mathrm{MD}$. Thus, as compared to $\mathrm{I}^{\mathrm{U}} \mathrm{U}-\mathrm{I}$ and $\mathrm{I}^{\mathrm{U}} \mathrm{U}-3$, the hard segments of $\mathrm{PU}-2$ may be mixed to more extent with ${ }^{3} \mathrm{BS}$ and P'EG soft segments, as shown in Figure 2. This probably lowers the degree of crystallization of PBS segments in PU-2, resulting in the lower $\mathrm{C}_{11}$ and smaller $\Delta \mathrm{H}_{\mathrm{m}}$ values.

The wide angle $\mathrm{X}$-ray diffraction experiment revealed that two peaks appeared simultaneously at $2 \theta$ values of approximately 19 and $22^{\circ}$ for all of the three different polyurethanes as well as for PBS as described in the previous papers., However, the diffraction peaks for the polyurethanes appear
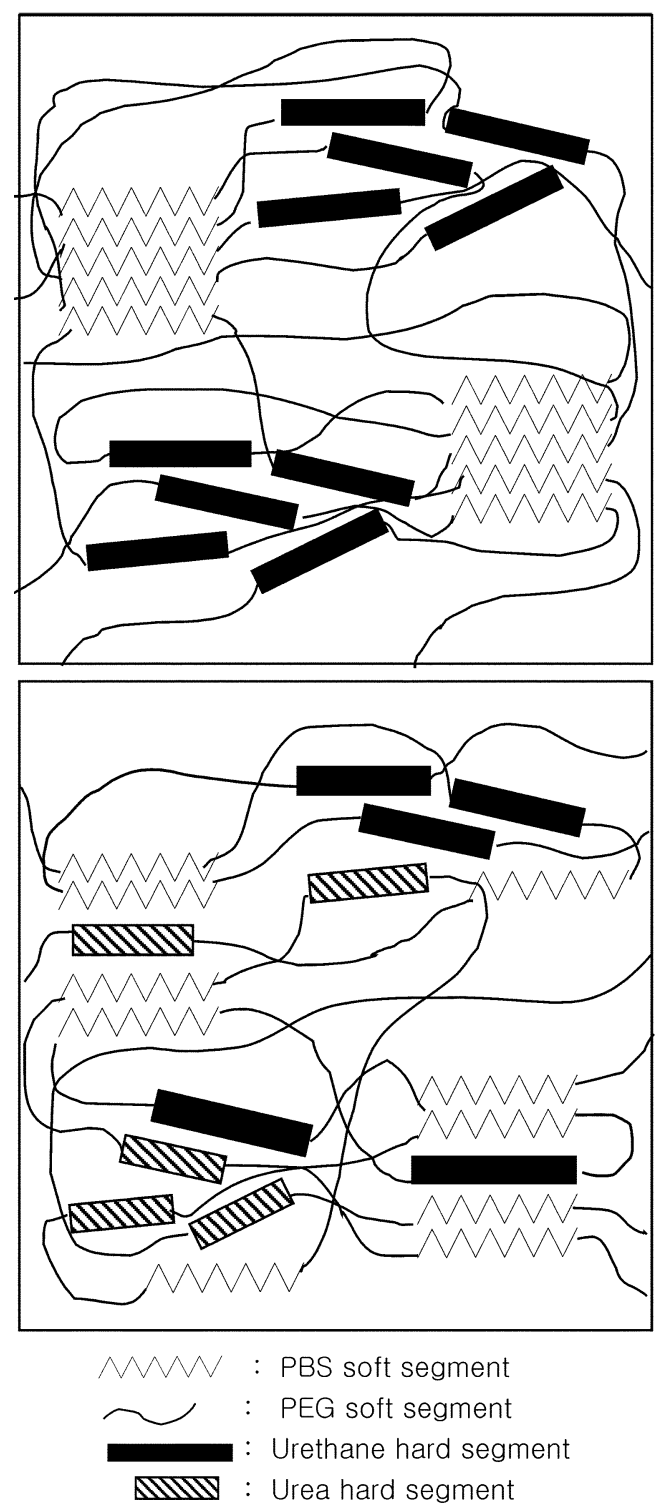

Figure 2. Schematic representation of polymer morphology: (a) Pl -1 and (b) Pll-2. less sharply than those for PBS and cannot be easily distinguished from one another. This experimental finding confirmed that the crystallinity of the polymers resulted from the PBS seginents and their crystal structures were not much affected by the P'EG and hard segments even though their $\mathrm{T}_{n 11}$ and $\Delta \mathrm{H}_{11}$ values are slightly different. The changes in the $\mathrm{I}_{\mathrm{m}}$ and $\Delta \mathrm{H}_{\mathrm{m}}$ values simply reflect variations in the degree of crystallization of PBS segments in the films.

The initial purpose of present research was to observe any change in physical properties of the polyurethanes when both $\mathrm{ED}$ and $\mathrm{BD}$ were used as chain extenders. Thin filıns (thickness, 0.8-1.0 nmm) of the polyurethanes were easily prepared by following the hot press method, while those of PBS could not be prepared since PBS was too brittle due to its low molecular weight. The tensile strengths of PU-2 and PU-3 were slightly greater than that of PU-I. The urea groups in the hard segments of $P U-2$ and $P U-3$ increase the intermolecular interactions due to the additional hydrogen bonding. The modulus behavior of the polymers can also be explained in terms of the hydrogen bonding interaction.

The sequence of elongation at break of the polymer filıns was observed to be $\mathrm{P}^{\mathrm{U}} \mathrm{U}-2>\mathrm{I}^{\mathrm{U}} \mathrm{U}-\mathrm{I}>\mathrm{PU}-3$. In fact, it is wellknown that in the case of polyurethane elastomers, the soft segments usually contribute to the high extension and elastic recovery while the hard segments contribute to the high modulus. ${ }^{10.11}$ The soft segments in this system are the same for the three different polymers. The molecular weights of the three different polymers are not much different from each other, either. First of all, the elongation of $\mathrm{PU} \mathrm{U}-\mathrm{I}$ film at break was much greater than those of PU-3 film. It is known that the elastic property of polyurethanes can be enhanced at the expense of tensile strength and modulus when diol is used instead of diamine as chain extender. ${ }^{12.15}$ As explained above, PU-1 contains urethane groups in its hard segments, but $\mathrm{P} U-3$ contains urea groups instead. The urea groups in PU-3 increase the degree of intermolecular hydrogen bonding and, consequently, its rigidity and brittleness.

Interestingly, the elongation of $\mathrm{PU}-2$ film at break was much greater than those of PU-I and PU-3 films. The elongation behavior of PU-2 film can be explained by a similar reason as that for the melting transition behavior. As proposed in Figure 2. PU-2 has more free PBS and urethane/ urea hard segments escaped from the corresponding PBS and hard domains, respectively, due to more phase mixing between the soft and hard segments. The more phase mixing is due to the mismatching between the urethane- and ureabased hard segments. The urethane and urea groups in the hard segment domains can form hydrogen bonding even though they cannot be crystallized due to the different isomeric structures of $\mathrm{H}_{12}$ MDI. The free segments of polymer chains are usually significantly entangled in the amorphous state. On stretching, however, the free segments become aligned on a common axis. This means that the elongation is largely affected by the free segments of amorphous state in elastomers. In other words, the more the free seginent content of polyurethane, the greater is the elongation of its film. Because of the mismatching between the urethane- and 
urea-based hard segments, PU-2 has more free segments than PU-1 and PU-3. leading to the significant elongation of its film.

\section{Conclusion}

Polyurethanes containing PBS and PEG as soft segments were synthesized by using chain extenders of $\mathrm{BD}(\mathrm{PU}-\mathrm{l})$. $\mathrm{BD} / \mathrm{ED}(1 / \mathrm{l})$ (PU-2), and ED (PU-3). The $\mathrm{T}_{\mathrm{m}}$ and $\Delta \mathrm{H}_{\mathrm{m}}$ values of PU-2 were smaller than those of PU-I and PU-3. The tensile strength and modulus of the polyurethane films were increased when ED was used as chain extender. On the other hand, the elongation at break of PU-2 film was much greater than that of either PU-1 or PU-3 film. The enhanced elongation of $\mathrm{PU}-2$ film is probably due to more free segments which result from the mismatching between the urethane- and urea-based hard segments. This strategy of using a mixture of diol and damine as chain extenders may be applicable to other polyurethane systems especially when the elastic property of polyurethanes containing crystalline soft segments needs to be enhanced significantly.
Acknowledgement. This research was supported by research funds of Chonbuk National University.

\section{References}

1. Albertsson, A. C; Ljungquist, O. J. J. Hacromol Sci. Chem. 1986. $A 23.411$

2. Albertsson. A. C.: Ljungquist. O. T. Acta Polmm. 1988. 39.95.

3. Reed. A. M.: Gilding. D. K. Polvmer 1981. 22. 499.

4. Kawai, F. Chit Rev Biotechol 1987, 6, 273.

5. Kawai, F.: Enokibara. S. J. Fennent. Biong 1996. 82, 575.

6. Lee. S.-I.: Lee, Y.-S.; Nahm, K. S.: Hahn. Y. B.: Ko. S.-B. Bull. Konan Chem. Soc. 2000. 21.1145.

7. Lee. S.-I.: Yu. S.-C.: Lee. Y.S. Pohm Legrad Stab. 2001. 72.81

8. Nagata. M.: Kiyotsukuri. T.: Takeuchi. S.: Tsutsumi. N.: Sakai. W. Polm. Im. 1997, 42,33.

9. Ahn. T. O.: Hong. I. P.: Kim. J. H.: Jeong, H. M. Polyner (Kona) 1990. 14,608

10. Szycher. M. Szycher's Handbook of Polymethanes. CRC Press: 1999.

11. Hepburn. C. Polvunthane Elastomens: Elsevier Applied Science 1992: $\mathrm{p} 65$

12. Li. F.: Zuo, J.; Dong, L.; Wang, H.: Luo, J.: Han, W.: Huo, Y. Eu: Polvm. J. 1998. 34. 59

13. Delpech. M. C.: Coutinho. F. M. B. Polyn. Test. 2000. 19. 939. 